13.1;13.3;07.3

\title{
Применение полимерных пленок с наночастицами серебра для улучшения спектральных характеристик фотоэлектрических преобразователей
}

\author{
(C) Л.С. Лунин ${ }^{1,2}$, О.В. Девицкий ${ }^{1,3}$, А.А. Кравцов ${ }^{1,3}$, А.С. Пащенко ${ }^{1,2}$ \\ ${ }^{1}$ Федеральный исследовательский центр Южный научный центр РАН, Ростов-на-Дону, Россия \\ ${ }^{2}$ Южно-Российский государственный политехнический университет (НПИ) им. М.И. Платова, Новочеркасск, Россия \\ ${ }^{3}$ Северо-Кавказский федеральный университет, г. Ставрополь, Россия \\ E-mail: lunin_Is@mail.ru
}

Поступило в Редакцию 15 октября 2019 г.

В окончательной редакции 15 октября 2019 г.

Принято к публикации 25 октября 2019г.

Разработан способ получения пленок поливинилбутираля с наночастицами серебра. Изучены свойства полученных пленок в качестве просветляющих покрытий для кремниевых фотоэлектрических преобразователей. Эксперименты выполнены на фотоэлектрических преобразователях с покрытием $\mathrm{Si}_{3} \mathrm{~N}_{4}$ и без него. Показано, что при максимальной концентрации наночастиц серебра $(7 \mathrm{mmol} / \mathrm{l})$ увеличение внешнего квантового выхода в спектральном диапазоне $500-1000 \mathrm{~nm}$ составило более $20 \%$ для образцов без слоя $\mathrm{Si}_{3} \mathrm{~N}_{4}$. В случае нанесения разработанных функциональных покрытий на фотопреобразователи с $\mathrm{Si}_{3} \mathrm{~N}_{4}$ квантовый выход в интервале $400-1000 \mathrm{~nm}$ увеличился в среднем на $10 \%$, а в диапазоне $320-400 \mathrm{~nm}-$ на $15-20 \%$.

Ключевые слова: солнечные элементы, плазмонный резонанс, наночастицы серебра, функциональные покрытия.

DOI: 10.21883/PJTF.2020.02.48955.18077

В настоящее время по всему миру все большее внимание уделяется проблеме перехода к чистым возобновляемым источникам электроэнергии. В частности, фотоэлектрические преобразователи (ФЭП) получили широкое распространение благодаря относительной дешевизне и значительному прогрессу в области технологии в течение последних 20 лет. В связи с этим особую важность приобретает задача увеличения эффективности ФЭП. На данный момент увеличение их эффективности достигается как за счет применения новых материалов, так и за счет разработки качественно новых конструкций. Не теряют актуальности задачи снижения потерь мощности на омических контактах путем оптимизации последовательного и параллельного сопротивления, а также уменьшения влияния эффекта термализации и отражения от поверхности ФЭП [1-3]. К отдельному способу увеличения эффективности ФЭП можно отнести нанесение на их поверхность функциональных покрытий $[4,5]$. Такие покрытия позволяют увеличить эффективность ФЭП без модификации конструкции и изменения технологии их производства. Наиболее широко используемыми для этих целей покрытиями являются $\mathrm{Si}_{3} \mathrm{~N}_{4}$ и $\mathrm{SiO}_{2}$. Они позволяют уменьшить потери на отражение поверхностями ФЭП до 2-3\%. Более перспективным может быть применение многофункциональных покрытий, которые одновременно сочетали бы в себе свойства антиотражающих покрытий (ARC) и позволяли расширить спектральную чувствительность и повысить квантовый выход ФЭП [6]. Такие функциональные покрытия могут быть созданы на основе полимерных пленок с наночастицами серебра [7-9]. Наночастицы серебра обладают рядом уникальных свойств, важнейшим из которых является поверхностный плазмонный резонанс $[5,6]$.

Цель настоящей работы заключается в получении функциональных покрытий на основе поливинилбутираля с наночастицами серебра (ПВБ-Ag), а также в исследовании их влияния на спектральные характеристики кремниевых солнечных элементов.

Первым этапом исследования являлось получение функциональных покрытий на основе ПВБ-Ag. Нанесение функциональных покрытий осуществлялось на стеклянные и кремниевые подложки.

Стабильные монодисперсные наночастицы серебра были получены в среде изопропилового спирта. В качестве прекурсора был использован $\mathrm{AgNO}_{3}$. За основу был взят классический метод синтеза наночастиц серебра путем восстановления боргидридом натрия, описанный в работах $[10,11]$. Далее готовился пленкообразующий раствор путем добавления различного количества золя серебра в раствор ПВБ в изопропиловом спирте. Для нанесения функциональных покрытий применялся так называемый метод „осушения“. Сущность этого метода состоит в том, что в кювету для нанесения пленки на специальной оснастке помещался образец, после чего при помощи перистальтического насоса объем кюветы заполнялся пленкообразующим раствором до полного погружения образца в раствор. Затем производилось откачивание всего объема раствора перистальтическим насосом с оптимальной скоростью. Далее образец под- 


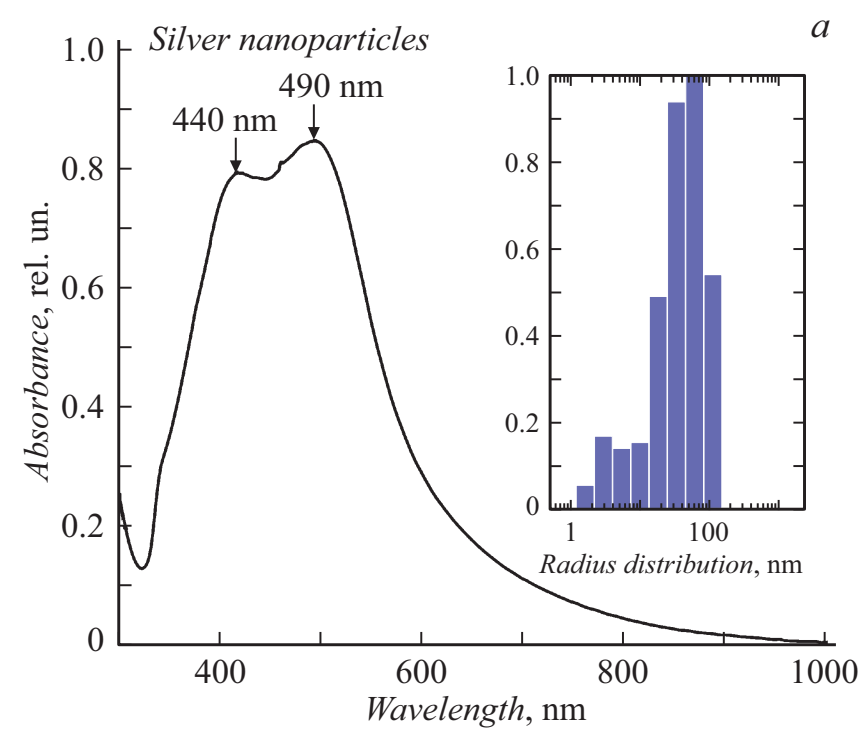

\begin{tabular}{|c|c|c|c|c|}
\hline Peak number & Area, $\mathrm{nm}^{2}$ & Mean, $\mathrm{nm}$ & Position & STD \\
\hline 1 & 0.062 & 2.698 & 3.015 & 0.750 \\
\hline 2 & 0.938 & 51.05 & 62.10 & 34.71 \\
\hline
\end{tabular}

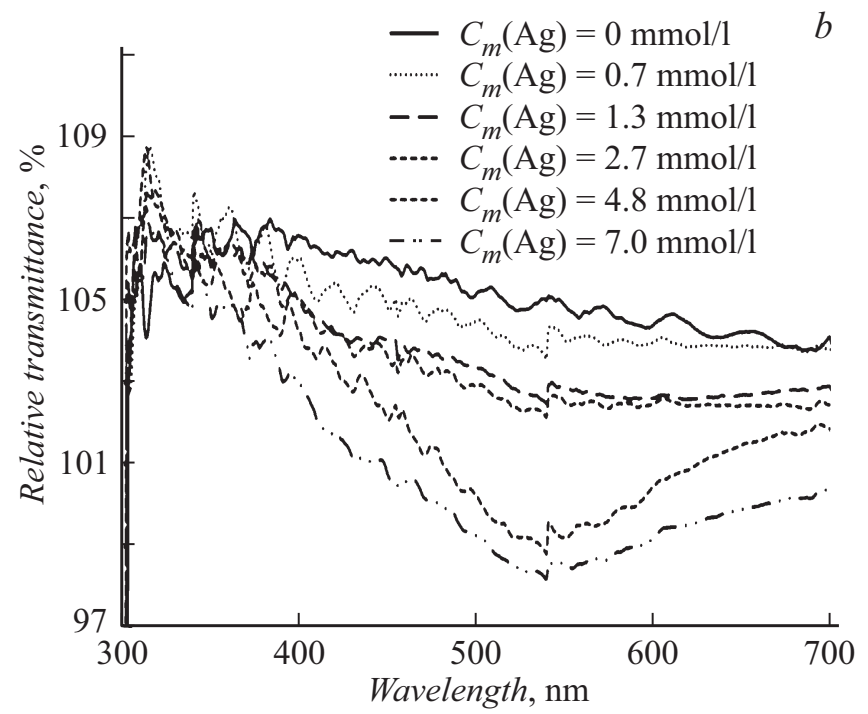

Рис. 1. Спектр поглощения золя серебра (на вставке гистограмма распределения гидродинамических радиусов наночастиц серебра) (a) и спектр пропускания пленок ПВБ- $\mathrm{Ag}$ на стекле (относительно образца сравнения из чистого стекла) (b).

вергался сушке на воздухе в течение $10 \mathrm{~min}$, после чего при необходимости проводилось повторное нанесение пленки. После нанесения пленка ПВБ-Ag на поверхности образцов имела равномерную толщину около $2 \mu \mathrm{m}$.

Оптические спектры поглощения исходных золей серебра и спектры пропускания пленок ПВБ-Ag на стекле были измерены на спектрофотометре СФ-56 (рис. 1). В спектре поглощения золя серебра (рис. 1,a) присутствуют два максимума на длинах волн 440 и $490 \mathrm{~nm}$. Согласно [12], подобный спектр поглощения характерен для кластеров сферических наночастиц серебра диа- метром $\sim 100 \mathrm{~nm}$. Методом фотонно-корреляционной спектроскопии на приборе Photocor Complex было установлено, что средний гидродинамический радиус наночастиц серебра составляет $51.05 \mathrm{~nm}$. Исходя из этого можно предположить, что полученные в рамках данного исследования наночастицы $\mathrm{Ag}$ будут проявлять выраженный эффект локализованного поверхностного плазмонного резонанса и эффект рассеяния оптического излучения на наночастицах, описанный в работе [13]. На спектрах пропускания (рис. 1,b), измеренных относительно чистого стекла без покрытий, можно увидеть эффект просветления от разработанных пленок ПВБ- Ag. На представленных спектрах интенсивность оптического излучения, пропущенного через стекло с покрытием ПВБ-Ag, выше интенсивности излучения, пропущенного через образец сравнения - чистое стекло. Этим объясняются значения светопропускания выше 100\%. Следует отметить, что при увеличении концентрации наночастиц серебра снижается коэффициент пропускания покрытий за счет собственного поглощения наночастиц серебра, однако эффект просветления сохраняется.

Далее был изучен эффект влияния локализованного плазмонного резонанса на поверхность материалов, попадающих в его поле действия. С помощью метода комбинационного рассеяния света (КРС) в геометрии обратного рассеяния $z(x x) z$ было проведено исследование функциональных покрытий ПВБ-Ag, нанесенных на монокристаллическую кремниевую подложку с ориентацией (100). Результаты приведены на рис. 2. Анализ спектров комбинационного рассеяния показал, что при увеличении концентрации наночастиц серебра происходит увеличение интенсивности полос при 236, $920-1030$ и $2963 \mathrm{~cm}^{-1}$, относящихся к многофононному рассеянию естественного диоксида кремния на поверхности кремниевой подложки. Проявление гигантского эффекта комбинационного рассеяния свидетельствует о наличии на поверхности световых ловушек, которые образуются из-за возникновения эффекта поля в наночастицах серебра [14].

На втором этапе исследования функциональные покрытия ПВБ-Ag наносились на высокоэффективные ФЭП производства корпорации SunPower с эффективностью преобразования солнечного излучения 22.2\%. Образцы ФЭП имели размер $125 \times 20 \mathrm{~mm}$, на фронтальной поверхности отсутствовала контактная сетка [9]. Функциональные покрытия наносились на образцы с промышленным антиотражающим слоем $\mathrm{Si}_{3} \mathrm{~N}_{4}$ (H-серия) и без него ( $C$-серия). Исследование свойств покрытий осуществлялось путем измерения спектральных зависимостей внешнего квантового выхода (EQY). Результаты приведены на рис. 3. Видно, что в обоих случаях наблюдается повышение EQY. Для $C$-серии образцов (рис. 3, $a$ ) отмечается больший эффект от разработанных функциональных покрытий в спектральном диапазоне 500-1000 nm. При этом следует отметить, что эффект от наночастиц серебра наиболее сильно проявляется при концентрациях выше $5 \mathrm{mmol} / 1$ (по сравнению с практически чистым слоем ПВБ). В интервале 400-500 nm прирост EQY объясняется плазмонным 


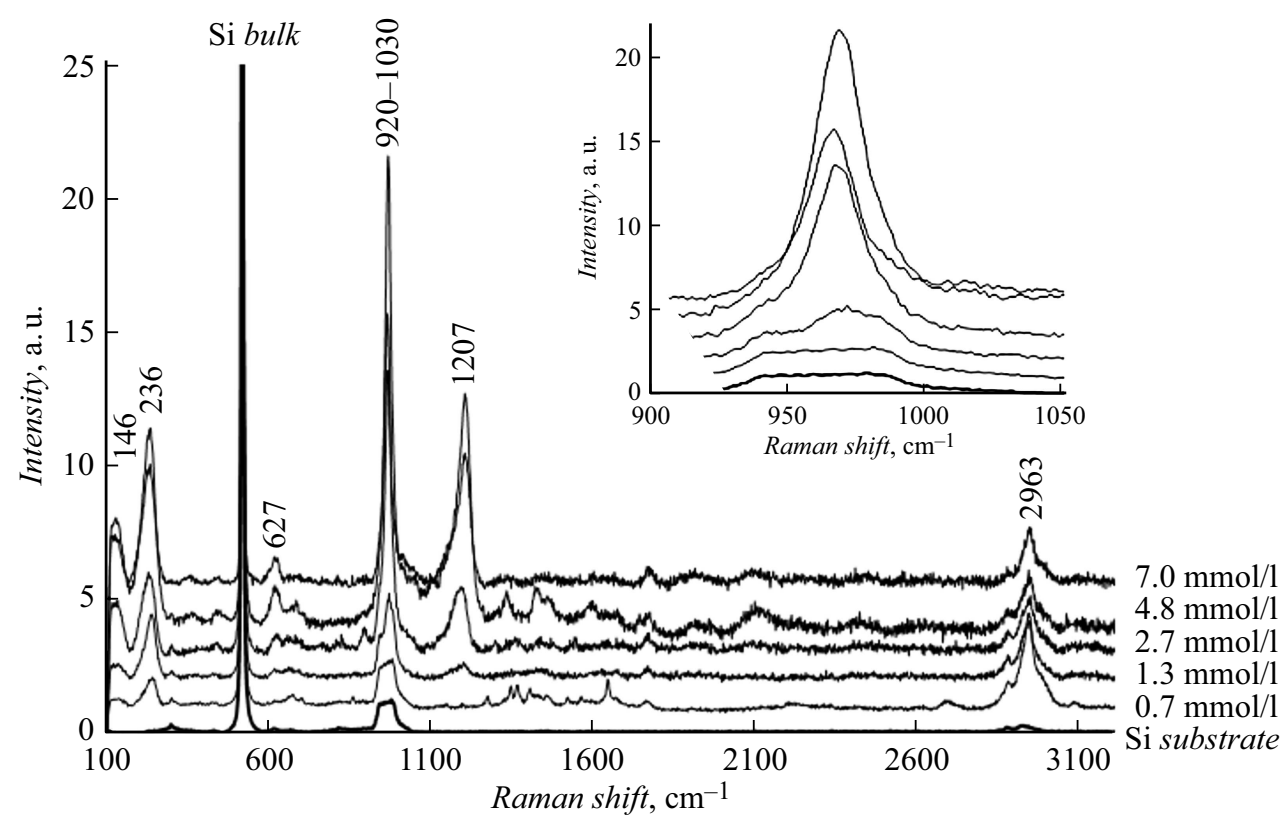

Рис. 2. Спектры КРС функциональных покрытий ПВБ с наночастицами серебра на подложке $\operatorname{Si}(100)$.
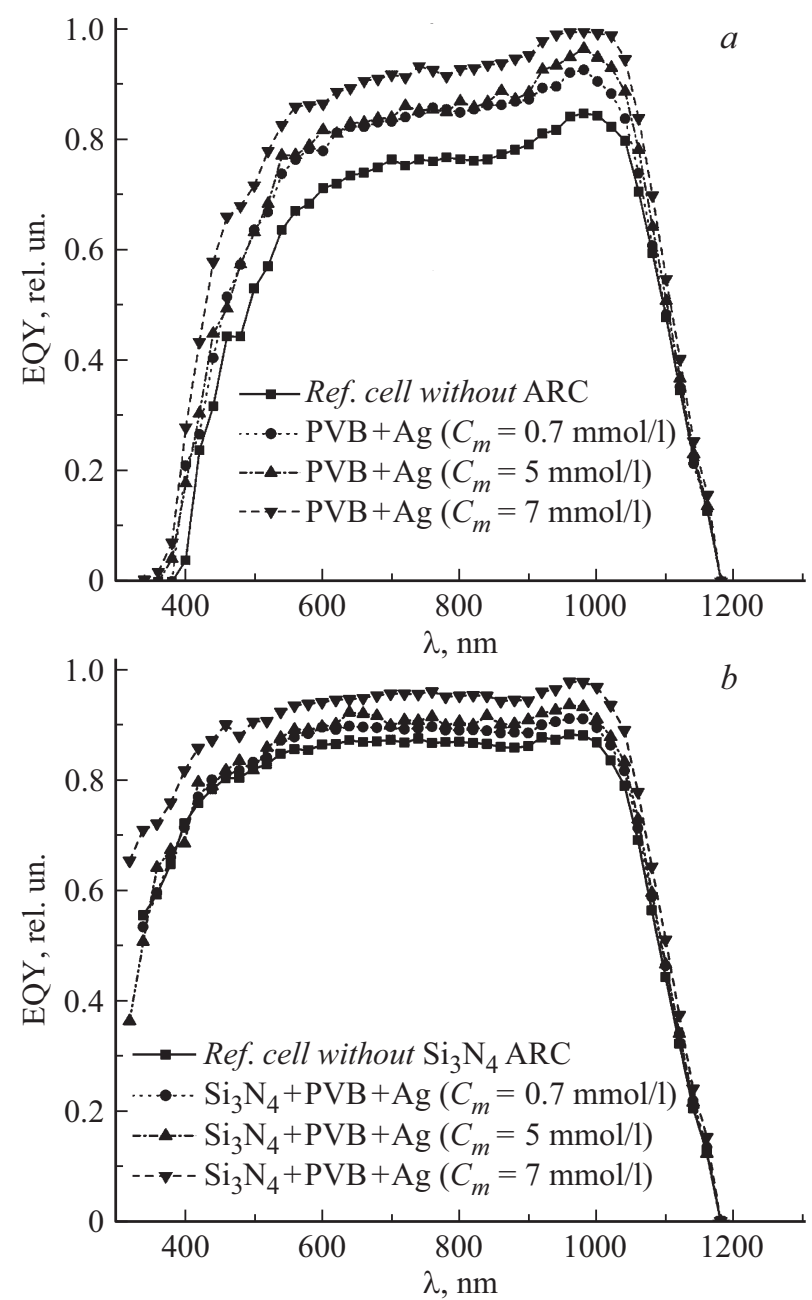

Рис. 3. Спектральные зависимости внешнего квантового выхода кремниевых солнечных элементов с функциональным покрытием ПВБ-Ag с различной концентрацией серебра. $a-$ $C$-серия, $b-H$-серия. резонансом на наночастицах Ag. Результаты измерений интегрального фототока показали его увеличение с 29.7 до $37.1 \mathrm{~mA} / \mathrm{cm}^{2}$ в условиях освещения АM $1.5 \mathrm{G}$ $\left(E=1000 \mathrm{~W} / \mathrm{m}^{2}\right)$.

Для $H$-серии образцов (рис. $3, b)$ наблюдается ожидаемый рост внешнего квантового выхода в интервале длин волн 320-1000 nm. Наибольшее увеличение EQY (на 15-20\%) происходит на спектральном участке 320-400 nm. В видимом и ближнем инфракрасном диапазонах прибавка во внешнем квантовом выходе составила около $10 \%$. Как и в случае образцов $C$-серии, максимальный эффект от просветляющих покрытий достигается при концентрациях Ag выше $5 \mathrm{mmol} / 1$. Измерение интегрального фототока для $H$-серии экспериментальных образцов показало его увеличение с 36.4 до $40.3 \mathrm{~mA} / \mathrm{cm}^{2}$ в условиях освещения АM $1.5 \mathrm{G}\left(E=1000 \mathrm{~W} / \mathrm{m}^{2}\right)$.

Проведенные экспериментальные исследования показывают, что пленки на основе ПБВ-Ag могут эффективно использоваться в качестве функциональных покрытий для кремниевых солнечных элементов. Экспериментально показано, что введение наночастиц серебра в пленки поливинилбутираля позволяет повысить внешний квантовый выход кремниевых солнечных элементов в интервале 320-1000 nm. Наибольший эффект наблюдается при концентрации наночастиц серебра в пленкообразующем растворе более 5 mmol/l.

\section{Финансирование работы}

Публикация подготовлена в рамках государственных заданий Федерального исследовательского центра Южного научного центра РАН на 2020 г. (номера госрегистрации 01201354240 и АААА-А19-119040390081-2). 


\section{Конфликт интересов}

Авторы заявляют, что у них нет конфликта интересов.

\section{Список литературы}

[1] Agrawal M., Rigorous F.M. // Prog. Photovolt.: Res. Appl. 2012. V. 20. N 4. P. 442-451.

[2] Haase C., Stiebig H. // Prog. Photovolt.: Res. Appl. 2006. V. 14. N 7. P. 629-641.

[3] Rumyantsev V.D., Davidyuk N.Yu., Chekalin A.V., Malevskiy D.A., Panchak A.N., Sadchikov N.A., Andreev V.M., Luque A. // IEEE J. Photovolt. 2005. V. 5. N 6. P. 1715-1721.

[4] Muhlschlegel P., Eisler H.J., Martin O.J.F., Hecht B., Pohl D. // Science. 2005. V. 308. N 5728. P. 1607-1609.

[5] Atwater H.A., Polman A. // Nature Mater. 2010. V. 9. N 3. P. 205-213.

[6] Ditlbacher H., Krenn J.R., Schider G., Leitner A., Aussenegg F.R. // Appl. Phys. Lett. 2002. V. 81. N 10. P. 1762 1764.

[7] Wang P.H., Theuring M., Vehse M., Steenhoff V., Agert C., Brolo A.G. // AIP Adv. 2017. V. 7. N 1. P. 015019.

[8] Wang P.H., Nowak R.E., Geißendörfer S., Vehse M., Reininghaus N., Sergeev O., von Maydell K., Brolo A.G., Agert C. // Appl. Phys. Lett. 2014. V. 105. N 18. P. 183106.

[9] Franklin E., Fong K., McIntosh K., Fell A., Blakers A., Kho T., Verlinden P.J. // Prog. Photovolt.: Res. Appl. 2016. V. 24. N 4. P. 411-427.

[10] Лунин Л.С., Лунина М.Л., Кравц,ов А.А., Сысоев И.А., Блинов А.В. // ФТП. 2016. Т. 50. В. 9. С. 1253-1257.

[11] Лунин Л.С., Лунина М.Л., Кравцов А.А., Сысоев И.А., Блинов А.В., Пащенко А.С. // ФТП. 2018. Т. 52. В. 8. C. $860-864$.

[12] Amendola V., Bakr O.M., Stellacci F. // Plasmonics. 2010. V. 5. N 1. P. 85-97.

[13] Becker J. Plasmons as sensors. Berlin: Springer, 2012. P. 5-38.

[14] Кайдашев В.Е., Лянгузов Н.В., Юзюк Ю.И., Кайдашев Е.M. // ЖТФ. 2012. Т. 82. В. 10. С. 85-89. 